\title{
Melanin Containing Neurofibroma: Case Report with evidence of Schwann Cell Origin of Melanin
}

\author{
BRIAN ANDERSON, AND DAVID M. ROBERTSON
}

\begin{abstract}
RÉSUMÉ: Nous rapportons un cas de neurofibrome contenant de la mélanine et qui se situait sur une racine spinale. La microscopie électronique de la tumeur montre que les cellules de Schwann néoplasiques sont douées de mélanogénèse. Malgré le fait que cette possibilité ait été mentionnée dans la littérature, une confirmation au niveau ultra-microscopque est rare.

Nous discutons également de l'identité possible entre "les naevi cellulaires bleus des racines spinales" et les tumeurs de la capsule des nerfs. II est possible que ces tumeurs pigmentées de la capsule des nerfs soient plus aggressives que les tumeurs non pigmentées, mais ce point est encore discutable.
\end{abstract}

SUMMARY: This case report describes a melanin-containing neurofibroma involving a spinal nerve root. Electron microscopy of the tumor show's that neoplastic Schu'ann cells are capable of melanogenesis. Although this capability is suggested in the literature, fen reports provide ultrastructural confirmation.

The likely' identity betw'een reported "cellular blue nevi of spinal nerve roots" and nerve sheath tumors is discussed. It is possible that pigmented nerve sheath tumors behave more aggressively than nonpigmented ones, although it is debatable.

From the Department of Pathology, Queen's University and Kingston General Hospital, Kingston, Ontario, Canada.

Reprint requests to: David M. Robertson, M.D., Department of Pathology, Queen's University, Kingston, Ontario, K7L 3N6, Canada.

\section{INTRODUCTION}

Melanin containing neurofibromas and Schwannomas have been reported (Bednar, 1957 and 1970; Hodson, 1961; Shillitoe, 1965; Dastur et al., 1967; Bird and Richards, 1968; Mandybur, 1974; Mennemeyer et al., 1978). It has been suggested that Schwann cells are capable of melanogenesis, and some reports provide supporting ultrastructural evidence (Spence et al., 1976; Hahn et al., 1976; Mennemeyer et al., 1978). The possibility that melanocytes, having failed to migrate to the periphery, produce melanin that is secondarily phagocytized by Schwann cells is favored by some (Shillitoe, 1965; Dastur et al., 1967; Mandybur, 1974). Microscopic similarities between nerve sheath tumors and blue nevi have suggested a common origin (Masson, 1951; Leopold and Richards, 1967; Bird and Richards, 1968; Merkow et al., 1969), and blue nevi involving spinal nerve roots have been reported (Graham et al., 1976).

This article describes a neurofibroma with heavily pigmented cellular areas. Melanin production within proliferating Schwann cells was confirmed by electron microscopy indicating that Schwann cells are capable of melanogenesis.

\section{CASE REPORT}

This 23 year old Caucasian male had complained of posterior left leg pain of radicular nature for several months. Examination revealed loss of muscle bulk in the left calf and an absent ankle jerk. Myelography suggested a herniated disc. Operation revealed an extradural, intraspinal black lesion admixed with the second sacral nerve root. The dura was not opened; the lesion was biopsied and the wound closed.

Several weeks later the patient was re-explored. A large tumor involving the second sacral nerve root was seen intradurally and passing extradurally through an expanded sacral foramen. A large portion was anterior to the sacrum. Only partial removal was possible. The tumor was sharply demarcated, greyish white with only discrete focal areas of solid black. Hemorrhage and necrosis obscured the site of previous surgery.

\section{MATERIALS AND METHODS}

Formalin fixed, paraffin embedded portions of each operative specimen were submitted to routine stains as well as reticulin, iron, melanin, and Bodian/luxol fast blue.

Fresh tissue was fixed in $3 \%$ glutaraldehyde, epon embedded, and cut in 60-90 millimicron sections for electron microscopy.

\section{PATHOLOGIC FINDINGS}

\section{Gross}

The first specimen consisted of multiple fragments of reddish-brown to black tissue weighing 5.3 grams. The second specimen was greyish with infrequent flecks of black resembling the first, admixed with areas of hemorrhage. It was firmer than the first and consisted of numerous fragments averaging $2 \times 1.5 \times 1 \mathrm{~cm}$., collectively weighing 25 grams.

\section{Light Microscopy}

Sections of the first specimen revealed a densely cellular tumor invading nerve and adjacent dorsal root ganglion. Constituent cells were spindle shaped and irregularly arranged into both compact and loose areas (Fig. 1). Occasional mitoses and 


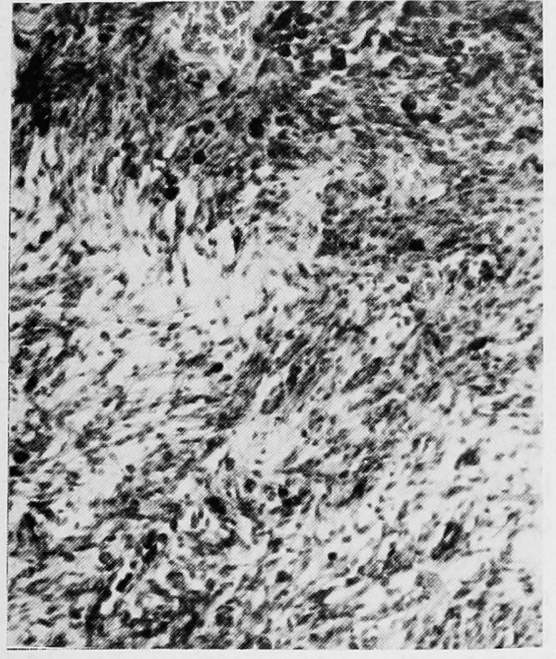

Fig. 1-Irregular arrangement of spindle shaped cells into loose and compact areas. (HPS X 63).

moderate nuclear pleomorphism were present. The tumor was moderately vascular with little supporting stroma, although a faint reticulin positivity was noted. Pigmentation was marked with many cells markedly distended, and interdigitating processes also containing pigment (Fig. 2). The pigment was histochemically demonstrated to be melanin. Necrosis was absent and axonal processes were not identified, except at the periphery

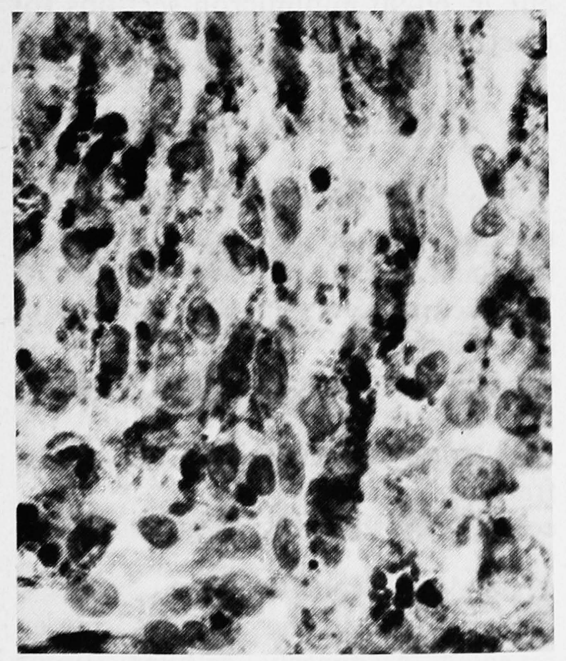

Fig. 2 - Spindle shaped cells with moderate nuclear pleomorphism. Pigment granules distending cell bodies and contained in interdigitating processes. (HPS X 400). where segments of the nerve root were present. Although Schwannoma was considered likely, diagnosis rested with electron microscopy.

The second specimen contained a less cellular tumor with individual cells containing flattened, wavy nuclei and sparse cytoplasm. A streaming arrangement of these cells, abundant collagen, and the demonstration of axonal processes indicated neurofibroma (Fig. 3). Pigmentation was notably absent except in sparse collections of cells that assumed the morphology of the first specimen.

\section{Electron Microscopy}

The melanin-containing portion consisted of elongate cells containing abundant mitochondria and granular endoplasmic reticulum. Nuclei often contained prominent nucleoli and their chromatin was dispersed to the nuclear membrane. Occasional desmosomes were identified. A continuous envelope of basement membrane surrounded each cell with adjacent cells often sharing the same membrane. Copious redundant basement membrane filled a predominantly empty extracellular space. Occasional finely granular material, but little collagen, was identified extracellularly. Numerous thin, basement membrane covered cell processes interdigitated among cell bodies. Occasional monuclear phagocytes were seen. Schwann cells in relation to myelinated axons wee sometimes seen (Fig. 4).

The basement membrane-invested cells and their processes contained numerous premelanosomes and melanosomes. These organelles varied considerably in size and shape. Premelanosomes were identified as membrane-limited vesicles presenting a matrix of parallel linear structures. As their melanin content increased, the internal structure becomes less apparent. A more electron dense organelle resulted, representing a mature melanosome (Fig. 5). Some Schwann cells showed considerable packing with melanin but compound melanosomes were not identified. Macrophages often contained typical compound melanosomes found by phagocytosis of pigment.

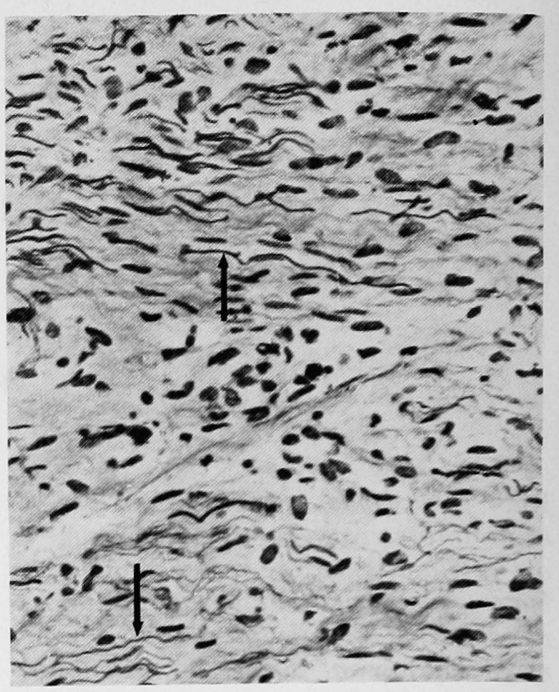

Fig. 3-Flattened wavy nuclei, streaming arrangement of cells and axonal processes (arrows) of neurofibroma part. (Bodian X 160).

The neurofibromatous part revealed cells with similar nuclei and cytoplasmic content except that melanin was absent. Basement membrane material was similar. The extracellular space was much wider with copious collagen. Numerous axons were seen in the cell processes (Fig. 6).

\section{DISCUSSION}

The predominant component of the lesion is a neurofibroma by both light and electron microscopic characteristics, (Waggener, 1966; Russell and Rubinstein, 1977). The more cellular and pigmented portion has characteristics of Schwann cell derivation. The ovoid nuclei, multiple thin cytoplasmic processes and redundant basement membrane material comply with previously reported neoplastic Schwann cell ultrastructure (Waggener, 1966; Cravioto, 1969). The finding of both premelanosomes and melanosomes confirms the presence of melanin manufacture within the constituent cells (Wellings and Siegel 1963, Breathnach 1969).

Reported cases of Schwann cell derived tumors containing melanin fail to present a uniform opinion as to the origin of the pigment. It is generally accepted that the Schwann cell and the melanocyte arise from 


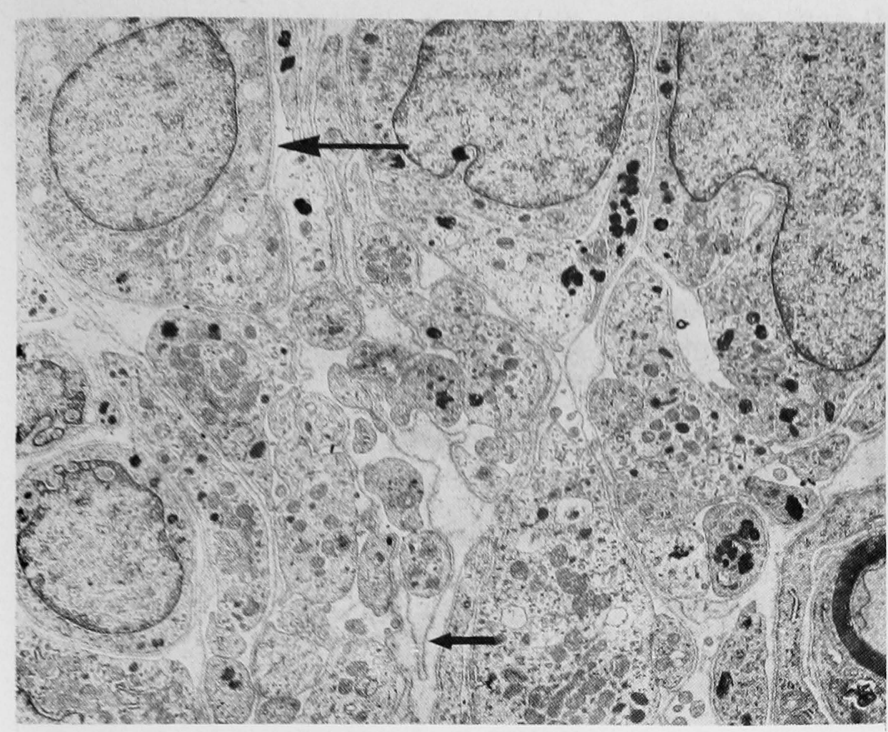

Fig. 4-Basement membrane covered cells (large arrow) with numerous processes. Redundant basement membrane material within a predominantly empty extracellular space (small arrow). Myelinated axon at lower right. (X 2900).

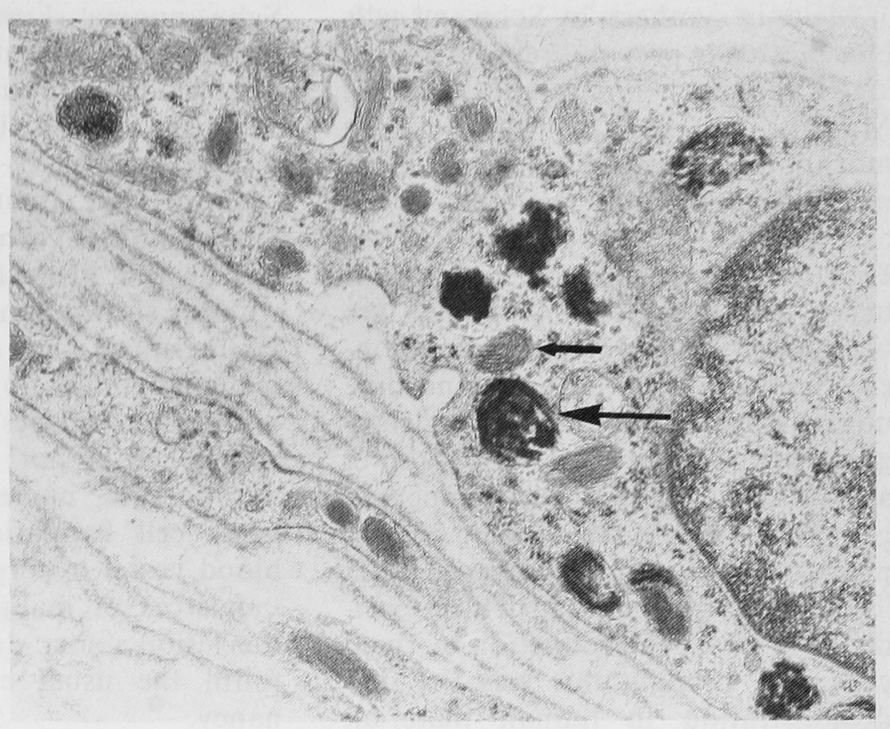

Fig. 5- Numerous premelanosomes (small arrow) and melanosomes (large arrow) within basement membrane covered cells (Schwann cells). (X 15000). common precursors in the neural crest. For this reason, melanin production by melanocytes failing to migrate to their peripheral sites is used to explain the presence of melanin in pigmented nerve sheath tumors. The melanocyte presents ultrastructurally as a cell without desmosomes, cytoplasmic tonofilaments, or basement membrane (Breathnach, 1969). As such, they are distinguishable from the Schwann cell. Melanocytes within pigmented nerve sheath tumors have been suggested by light microscopy, but ultrastructural confirmation has not been reported (Hodson, 1961; Dastur et al., 1967). There have been no definite reports of basement membrane material in tumors related to melanocytes (Spence et al., 1976). The ability of Schwann cells to phagocytize is well recognised (Dastur et al., 1967; Russell and Rubinstein, 1977). If melanin were phagocytized, it should exist as membrane-bound collections of melanosomes within the cytoplasm of Schwann cells (Wellings and Siegel, 1963; Breathnach, 1969). No melanin phagocytosis by Schwann cells was seen in this tumor.

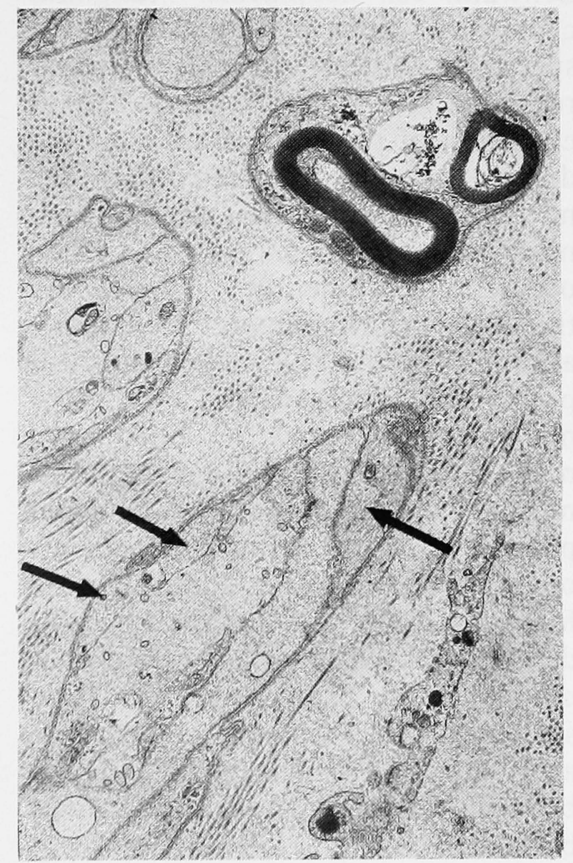

Fig. 6(a) - Wide extracellular space containing collagen admist proliferating Schwann cells. Note myelin figures within one of the Schwann cells. Note multiplicity of Schwann cell processes within common basement membrane (arrows). (X 10,000)

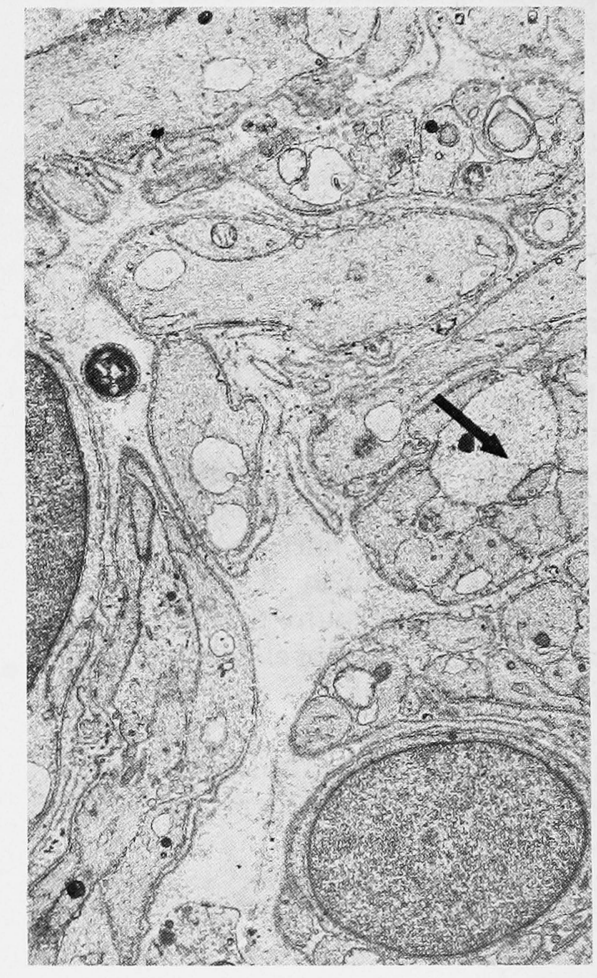

Fig. 6(b)-Multiple Schwann cell processes and occasional unmyelinated axons (arrow) typical of neurofibroma. (X 10,000). 
Melanin synthesis by Schwann cells is suggested in previous reports (Nakai and Rappaport, 1963; Shillitoe, 1965; Mandybur, 1974). Melanosome morphology compatible with actual melanin production is noted in the case report of Mandybur (1974). Ethyl-nitrosurea-induced malignant nerve sheath tumors in animals are occasionally pigmented and component Schwann cells have melanosome ultrastructure compatible with melangenesis (Spence et al., 1976). Hahn et al., (1976) reported a pigmented ganglioneuroblastoma within which pigmented Schwann cells were found. They provided ultrastructural evidence of melanin production by these cells, and thought this was the first demonstration in human material. Mennemeyer et al., (1978) reported in abstract form three cases of pigmented nerve sheath tumors involving spinal nerve roots. They stated that evidence of melanin synthesis was present in cells with both Schwann cell and melanocyte characteristics. The present case has cells with Schwann cell characteristics showing melaninproducing capabilities in support of previous demonstrations.

The origin of the blue nevus has been a subject of controversy. Masson (1951) popularized the notion that they originated from Schwann cells. Ultrastructural reports of cellular blue nevi of skin revealed features indistinguishable from Schwann-cell neoplasms, except for the melanin content (Nakai and Rappaport, 1963; Merkow et al., 1969). Blue nevi arising from spinal nerve roots have not been subjected to ultrastructural study. The similarity of blue nevi and Schwannoma by light microscopy is also notable (Graham et al., 1976). Such considerations require that the lesions at least be considered closely related or perhaps identical.

The occurrence of focal hypercellular areas within an otherwise typical neurofibroma together with the occasional mitoses and nuclear pleomorphism seen raises the questin of malignancy.

Russell and Rubinstein (1977) noted malignant change in a neurofibroma to be rare. They described a neurofibroma containing a small Schwannoma, and reported that the
Schwannoma showed signs of early malignancy. The more usual malignant change in a neurofibroma is towards neurofibrosarcoma and distant metastases from such lesions occur. They stated that benign Schwannomas can contain mitoses and degrees of nuclear pleomorphism without showing malignant behavior. Furthermore, they can assume highly malignant local appearances without distant metastases, although local recurrence is not uncommon. High mitotic rate, nuclear pleomorphism, giant cell formation, necrosis, and blood vessel hyperplasia are taken as indicators of malignancy. Therefore, the lesion under discussion does not fulfill the usual criteria for malignancy.

The presence of melanin synthesis within the tumor demands closer consideration of the question of malignancy. Melanotic nerve sheath tumors showing a marked tendency to local recurrence have been reported (Graham et al., 1976). These authors favored blue nevus as the diagnosis in their cases, but noted a similarity to Schwann cell neoplasms. Malignant change was either present in the initial specimens or evolved as the tumor recurred. They thought that malignant evolution of the blue nevus had been demonstrated and suggested that blue nevi of spinal nerve roots might show a more malignant behavior than those occurring peripherally. Considering the likely identity between blue nevus and Schwann cell neoplasms as previously discussed, and noting the malignant potential of blue nevi, malignancy in the lesion described must remain a consideration. It is not possible to make definite judgements on this report. The clinically and histologically malignant lesions described could represent melanomas or malignant Schwannomas. Ultrastructural study was not undertaken, and without it definite distinction between these two possibilities cannot be made.

\section{REFERENCES}

BEDNAR, B. (1957). Storiform neurofibromas of the skin, pigmented and nonpigmented. Cancer, (Philad.), 10: 368-376.
BEDNAR, B. (1970). Storiform neurofibroma in the core of naevocellular nevi. Journal of Pathology 101: 199-201.

BIRD, C. C., RICHARDS, D. B. (1968). The histogenesis of pigmented neurofibromas. Journal of Pathology 97: 631-637.

BREATHNACH, A S. (1969). "Normal and abnormal melanin pigmentation of the skin" in Pigments in Pathology (WOLMAN, M., ed.) Academic Press, New York.

CRAVIOTO, H. (1969). The Ultrastructure of acoustic nerve tumors. Acta Neuropathologica (Berlin) 12: 116-140.

DASTUR, D. K., SINH, G., PANDYA, S. K. (1967). Melanotic tumor of the acoustic nerve. Case report. Journal of Neurosurgery 27: 166-170.

GRAHAM, D. I., PATERSON, A., MCQUEEN, A., MILNE, J. A., URICH, H. (1976). Melanotic tumors (blue nevi) of spinal nerve roots. Journal of Pathology 118: 83-89.

HAHN, J. F., METSKY, M. G., A. B., SPERBER, E. E. (1976). Pigmented ganglio-neuroblastoma: Relations of melanin and lipfuscin to Schwannomas and other tumors of neural crest origin. Journal of Neuropathology and Experimental Neurology 35: 393-403.

HODSON, J. J. (1961). An intra-osseus tumor combination of biological importance invasion of a melanotic Schwannoma by an adamantinoma. Journal of Pathology and Bacteriology 82: 257-266.

LEOPOLD, J. G., RICHARDS, D. B. (1967). Cellular blue nevi. Journal of Pathology and Bacteriology 94: 247-255.

MANDYBUR, T. I. (1974). Melanotic nerve sheath tumors. Journal of Neurosurgery 41 : 187-192.

MASSON, P. (1951). My conception of cellular nevi. Cancer 4: 9-38.

MENNEMEYER, R., HAMMAR, S., TYFUS, J. S., RAISIS, J. E., HALlMAN, K. O., BOCKUS, D. (1978). Melanotic Schwanoma: Clinical and ultrastructural studies of three cases with evidence of intracellular melanin synthesis. Laboratory Investigation 38: $3,357$.

MERKOW, L. P., BURT, R. C., HAYESLIP, D. W., NEWTON, F. J., SLIFKIN, M., PARDO, M. (1969). A cellular and malignant blue nevus: a light and electron microscopic study. Cancer 24: 888-896.

NAKAI, T., RAPPAPORT, H. (1963). A study of the histogenesis of melanotic tumors resembling cellular blue nevi: the evidence in support of their neurogenic origin. American Journal of Pathology 43: 175-199.

PINEDA, A. (1964). Submicroscopic structure of acoustic tumors. Neurology 14; 171-184.

RUSSELL, D. S., RUBINSTEIN, L. J. (1977). Pathology tumors of the nervous system. Edward Arnold (Publishers) Ltd., 372-399.

SHILLITOE, A. J. (1965). Melanotic Schwannoma. Journal of Pathology and Bacteriology 90: 667-668. 
SPENCE, A. M., RUBINSTEIN, L. J., CONLEY, F. K., HERMAN, M. M. (1976). Studies on experimental nerve sheath tumors maintained in tissue and organ culture systems. Acta Neuropathologica (Berlin) 35: 27-45.
WAGGENER, J. D. (1966). Ultrastructure of bening peripheral nerve sheath tumors. Cancer (Philad.) 19: 669-709.
WELLINGS, S. R., SIEGEL, B. V. (1963). Electron microscopic studies on the subcellular origin and ultrastructure of melanin granules in mammalian melanomas. Annals of the New York Academy of Sciences 100: 548-568. 